\title{
The association between the functional incapacity of the older adult and the family caregiver's burden ${ }^{1}$
}

\author{
Edileuza de Fátima Rosina Nardi² \\ Namie Okino Sawada ${ }^{3}$ \\ Jair Licio Ferreira Santos ${ }^{4}$
}

Objective: to identify the association between the older adult's functional capacity and the caregiver's burden. Method: a cross-sectional, quantitative study, undertaken in a municipality in the north of the Brazilian state of Paraná, with 178 older adults with functional incapacity, and their caregivers. The Functional Independence Measure was used for evaluating the older adults' functional capacity, and the Zarit Burden Interview was used for evaluating the caregiver burden, with the results being analyzed quantitatively. The majority of the older adults were females, widowed, with a mean age of 79.9 years old, and needing assistance for up to $50 \%$ of the daily living tasks. The majority of the caregivers were females, daughters, married, and had a mean age of 56.7 years old. Result: the majority of the caregivers reported moderate burden; the men presented higher probabilities of lower burden than the women; and the more independent the older adult was, the higher the probabilities of the caregiver having low burden. Conclusion: encouraging actions directed at the promotion of active and healthy ageing centered on the maintenance of functional capacity and the older adult's autonomy, and implanting strategies for the organizing of care in the home which include the caregiver's health, can contribute to minimizing the effects of burden and improve quality of life.

Descriptors: Frail Elderly; Caregivers; Cost of Illness.

\footnotetext{
${ }_{1}^{1}$ Paper extracted from doctoral dissertation "Rede e apoio social, sobrecarga e qualidade de vida de cuidadores familiares de idosos com incapacidade funcional" presented to Escola de Enfermagem de Ribeirão Preto, Universidade de São Paulo, WHO Collaborating Centre for Nursing Research Development, Ribeirão Preto, SP, Brazil.

${ }^{2}$ PhD, Professor, Universidade Norte do Paraná, Arapongas, PR, Brazil.

${ }^{3} \mathrm{PhD}$, Associate Professor, Escola de Enfermagem de Ribeirão Preto, Universidade de São Paulo, WHO Collaborating Centre for Nursing Research Development, Ribeirão Preto, SP, Brazil.

${ }^{4}$ PhD, Full Professor, Faculdade de Medicina de Ribeirão Preto, Universidade de São Paulo, Ribeirão Preto, SP, Brazil.
}

Corresponding Author:

Edileuza de Fátima Rosina Nardi

Universidade Norte do Paraná

Rodovia PR-218, km 1

Jardim Universitário

CEP: 86702-670, Arapongas, PR, Brasil

E-mail: edileuzanardi@yahoo.com.br 


\section{Introduction}

Although human ageing should not be considered synonymous with illness and dependence, the growth of the elderly population increases the number of individuals who experience situations of physical and emotional frailty, there being a greater predisposition to pathological conditions, generally chronic, which if not treated or controlled adequately, can lead to the loss of autonomy and to functional capacity ${ }^{(1-2)}$.

In spite of the conceptual diversity, the definition of functional capacity is related to the individual's difficulty in carrying out basic or more complex tasks of daily living, which leads him or her to limit or restrict his or her social roles, besides the need for care and, consequently, for a person to help in carrying out these tasks - a caregiver ${ }^{(1)}$. Thus, the caregiver is considered as the person from the family or community who provides care to another person of any age, bed-ridden, with physical or mental limitations, with or without remuneration ${ }^{(3)}$

Simultaneously with this scenario of care, in particular the care for older adults, the Senior Citizens' Statute supports social reintegration, the exercising of citizenship, and the right to remain with one's family ${ }^{(4)}$, which transforms the family environment into a therapeutic environment, inserting the figure of the family caregiver into the healthcare setting. It stands out that the family caregiver, in most cases, is the person who is closest to the person needing care, that is, the closer they are related, the higher the individual's chances of becoming responsible for the care ${ }^{(5)}$.

One can, however, perceive the subjectivity which is part of the meaning of care, wrapped in each family's beliefs and values, which can be presented by the caregiver with either positive or negative aspects. The positive aspects include the feeling of a duty being accomplished, self-satisfaction, and reciprocity; however, those which predominate are related to the negative aspects, mainly arising from burden, family conflicts, and insecurity. These factors deserve to be highlighted, as they may impact on the caregiver's health and, consequently, on the care given, placing the older adult in a position which is more vulnerable to intrafamily violence and to institutionalization(6).

As a result, it is common for family caregivers to present feelings of guilt, anger, sadness, tiredness, anxiety and despair, as they often carry out activities without adequate guidance or support; when added to the demands on economic resources, family or personal organization, distress, conflicts and the accumulation of tasks, among others, this can create burden ${ }^{(7-8)}$.

It is emphasized that there are various factors which contribute to burden arising from the care process, given that it is a multidimensional concept in which stress, negative feelings, difficulties originating in the act of caring, economic factors and factors related to the caregiver's physical and mental health can predominate. Moreover, in spite of the caregivers not perceiving the burden in the same intensity, often they take on tasks for which they are not prepared - in addition to neglecting care for themselves, leading them to present physical and emotional illnesses ${ }^{(9)}$. The act of caring, therefore, has been conceptualized as an important stressing factor and, added to the chronic nature of caring for an older adult, without a defined duration, is associated with negative repercussions of caring, influencing the physical and psychological health of the person who provides the care ${ }^{(10)}$.

This burden is influenced, mainly, by organic and emotional factors related to the caregiver and to the older adult with incapacity, or by the structural conditions of the care environment and of the social support and the health support available for the family. These influences, associated with the concern about the progression of the older adult's health, can increase the tension in the family environment, interfering in the coexistence between its members ${ }^{(11)}$.

As time passes, as the older adult's debility and dependence increase, the duties of caring can change, requiring greater efforts to meet the needs which accompany the reduction in the older adult's functional capacity. Thus, as a result of the repercussions of caring, and the state of vulnerability to which the caregiver is exposed, physical, psychological and/or social strain can appear and, consequently, create burden for the person caring, which lies behind the choice of this issue for the present study.

Therefore, with the aim of contributing to the discussions on this issue, the present study's objective was to identify the association between the older adult's functional capacity and the burden on the family caregiver.

\section{Methods}

This is a descriptive, cross-sectional study, with a quantitative character, undertaken in a municipality in the north of Parana. For the selection of the subjects, a survey was initially carried out in a register of older adults 
in the Family Health Strategy, in which was included the need for a family carer, a total of 391 older adults being found in whom there was at least one dependence in Basic Activities of Daily Living (BADL) and who needed a family caregiver in order to undertake these. Afterwards, to determine the sample size, a confidence interval of $99 \%$ was considered, for a prevalence of $50 \%$ of older adults who presented at least one dependence in the Basic Activities of Daily Living (BADL). With these parameters, one obtains $n=166$. However, because the older adult with functional incapacity is a population in which possible losses and refusals may occur, 20\% was added to the sample, resulting in a requirement of 199 older adults.

The participants were selected randomly from among the caregivers for older adults in the records kept by the municipality's Family Health Strategy (ESF) Teams. The criteria for each participant's inclusion in the study were: to have been the principal family caregiver for a dependent older adult for at least six months; to be aged over 18 years old, to live with the older adult, and not to have been trained in the area of health.

Data collection took place between July and September 2011, in home visits, using a two-part instrument, to obtain information referent to the older adult and to the caregiver. In the identification of the older adults, an instrument was used for collecting socio-demographic information, and the Functional Independence Measure (FIM) was used for assessing functional capacity.

The FIM is a widely-used resource in older adults, and is an instrument for evaluation of incapacity in patients with functional restrictions of various origins. In its validation in Brazil it was shown to be an instrument which is sensitive to the functional gains developed during the outpatient rehabilitation program ${ }^{(12)}$.

The FIM evaluates 18 tasks, classified in six dimensions and two subdivisions: motor and cognitive. In the motor FIM, the values vary from 13 to 19 , while the cognitive FIM values vary from 5 to 35 . Thus, in the total FIM, the values vary from 18 to 126 , which can be divided into four sub-scores, according to the total score obtained: a) 18 points: complete dependence (total assistance); b) 19-60 points: modified dependence 1 (assistance with up to $50 \%$ of the task); c) $61-103$ points: modified dependence 2 (assistance with up to $25 \%$ of the task); d) $104-126$ points: complete/modified independence(12). Therefore, the lower the score, the higher the level of dependence and the worse the older adults' functional performance ${ }^{(12)}$.
In relation to the family caregiver, for data collection, an instrument was used with questions on socio-demographic and economic data, in addition to evaluation of the burden, the Zarit Burden Interview (ZBI) - an instrument with twenty-two items which assesses the impact perceived by the caregiver on physical and emotional health, social activities, and financial conditions. The scale's total score is obtained by summing all the items, and varies between 0 and 88 . The result was evaluated in accordance with how many points there were in the score, in which the higher the score, the higher the caregiver burden ${ }^{(13)}$.

The ZBI is an instrument widely used for assessing caregiver burden. In Brazil, it was translated into Portuguese and validated in a study with informal caregivers for individuals with mental illnesses ${ }^{(14)}$.

In this study, cut-off points were used for burden, with 0 to 20 points corresponding to low or no burden; from 21 to 40 points corresponding to moderate burden; moderate to severe burden was scored between 41 and 60 points, and, finally, severe burden is found between 61 and 88 points ${ }^{(13)}$

For analysis of the data, bivariate and multivariate analysis was used. In the bivariate analysis, the Test of association was used, through the Chi Squared and the Fisher test, to test possible associations of interest and to evidence significant differences. In relation to the Multivariate analysis, the multivariate technique was used to analyze the effect of each variable taken to be independent on the dependent variable, in the presence of all the others. The technique selected was logistic regression and the Odds Ratio was chosen as the element to evidence the association of the factors with the outcome. To facilitate the analysis and interpretation of the results in the logistic regression, the variables were dichotomized - reduced to two categories: one reference and one contrast. In the model used, factors were studied which could be associated with caregiver burden, dichotomized in Moderate and Severe (Reference) and Low or None (Contrast).

The study respected the recommendations of Resolution 196/96, regulated by the National Health Council, and the project was submitted for approval by the Research Ethics Committee of the Universidade Norte do Paraná (UNOPAR), being approved under Decision 0049/10. The data collection, along with the registration of the older adults by the Family Health Strategy teams, was authorized by the municipality's Municipal Health Department. Through the Terms of Free and Informed Consent, the study subjects were 
informed about the research's objectives and their right to refuse to participate at any point during its carryingout, it being guaranteed that they would not be penalized for so doing and that they would not be rewarded in any way for participating in the study.

\section{Results}

Of the 199 older adults who were selected to participate in the study, 178 caregivers participated; there was a loss of $10.5 \%$, as a result of 21 caregivers being excluded, who did not meet the inclusion criteria for the following reasons: four caregivers had been providing care for less than six months; three caregivers had training in the area of nursing; six caregivers were family members, but did not cohabit with the older adult; and eight caregivers were excluded because the older adults for whom they cared had died.

Regarding the older adults, the majority were female $(57.3 \%)$, widows $(51.7 \%)$, with a mean age of 79.9 years old ( $s d=9.1$ ) varying between 61 and 103 years old. The majority were in the age range of 80 years old and over (48.3\%), thus configuring a population of more elderly older adults. When the principal reason for dependence was analyzed, it was observed that among the reasons most mentioned, the
Cerebrovascular Accident (CVA) was the most prevalent $(37.0 \%)$, followed by externally caused fractures with $15.2 \%$, with falls being the main cause of the fractures.

Regarding the older adult's Functional Independence Measure (FIM), the mean motor FIM score was 41.6 $(s d=22.5)$, while that for the cognitive-social FIM was 21.7 ( $\mathrm{sd}=8.1$ ) and, finally, the total FIM was 63.4 ( $s d=28.3$ ). According to the level of dependence, based on the FIM, the majority of the older adults who participated in the research are classified as having modified dependence, with $46.7 \%$ having modified dependence 1 , needing assistance of up to $50 \%$ to carry out tasks, and $42.1 \%$ with modified dependence 2 , needing assistance with up to $25 \%$ of the tasks.

In relation to this study's family caregivers, the majority were female $(90.4 \%)$, daughters $(48.8 \%)$, married $(76.4 \%)$ with a mean age of 56.7 years old ( $s d=13.7)$, with the minimum age being 21 , and the maximum being 85 . It was identified in this study that $45.4 \%$ of the caregivers were aged over 60 years old. Moreover, in analyzing the caregiver age in relation to the age of the older adult, as shown in Table 1, the test of association using the Chi-Squared test showed a significant association $(p<0.05)$, it being observed that older caregivers care in a greater proportion, for more elderly older adults.

Table 1 - Number and percentage of family caregivers for older adults with functional incapacity, according to the age of the older adult and the age of the caregiver, Arapongas, Paraná (PR), Brazil, 2011

\begin{tabular}{|c|c|c|c|c|c|c|}
\hline \multirow[b]{2}{*}{ Age of older adult (in years) } & \multicolumn{6}{|c|}{ Age of caregiver (in years) } \\
\hline & $\begin{array}{c}20 \text { to } 39 \\
n(\%)\end{array}$ & $\begin{array}{c}40 \text { to } 49 \\
n(\%)\end{array}$ & $\begin{array}{c}50 \text { to } 59 \\
n(\%)\end{array}$ & $\begin{array}{c}60 \text { to } 69 \\
n(\%)\end{array}$ & $\begin{array}{l}\geq 70 \\
\mathrm{n}(\%)\end{array}$ & $\begin{array}{l}\text { Total } \\
\text { n (\%) }\end{array}$ \\
\hline 60 to 69 & $7(38.89)$ & $5(12.50)$ & $3(6.98)$ & $10(23.26)$ & $2(95.88)$ & $27(15.17)$ \\
\hline 70 to 79 & $9(50.00)$ & $23(57.50)$ & $15(34.88)$ & $11(25.58)$ & $12(35.29)$ & 70 (39.33) \\
\hline 80 to 89 & $1(5.56)$ & $9(22.50)$ & $19(44.19)$ & $12(27.91)$ & $13(38.34)$ & $54(30.34)$ \\
\hline$\geq 90$ & $1(5.56)$ & $3(7.50)$ & $6(13.95)$ & $10(23.26)$ & $7(20.59)$ & $27(15.17)$ \\
\hline Total & $18(100)$ & $40(100)$ & $43(100)$ & $43(100)$ & $34(100)$ & $178(100)$ \\
\hline
\end{tabular}

Pearson $\chi^{2}(12)=32.0136$ $\mathrm{p}=0.001$

Regarding economic classification, according to the Brazilian Association of Research Companies $(A B E P)^{(15)}$, it was found that $33.1 \%$ of the caregivers fit in the economic classes $\mathrm{C} 1$ and $\mathrm{C} 2$. However, according to the ABEP criteria, $51.6 \%$ of the caregivers are in the economic classifications C, D and E, and $48.4 \%$ in classifications $A$ and $B$.

In the evaluation of burden, among the caregivers it was identified that $102(57.3 \%)$ had moderate burden; that 44 (24.7\%) had low burden; 28 (15.7\%) had moderate to severe burden, and only $4(2.2 \%)$ caregivers had severe burden. The application of the Zarit Scale produced results with good internal consistency evaluated by the Cronbach Alpha, which attained 0.80 . The burden presented a mean of $30.6(s d=13)$.

When the burden and the sex of the caregiver were associated, the data from Table 2 showed a statistically-significant result in burden related to sex, in which the women reported greater burden than the men $(p<0.005)$. 
Table 2 - Distribution of burden of family caregivers for older adults with functional incapacity, according to the sex of the caregiver, Arapongas, PR, Brazil, 2011

\begin{tabular}{|c|c|c|c|c|c|c|}
\hline \multirow{3}{*}{ Burden } & \multicolumn{4}{|c|}{ Sex of caregiver } & \multirow{2}{*}{\multicolumn{2}{|c|}{ Total }} \\
\hline & \multicolumn{2}{|c|}{ Female } & \multicolumn{2}{|c|}{ Male } & & \\
\hline & $\mathbf{N}$ & $\%$ & $\mathbf{N}$ & $\%$ & $\mathbf{N}$ & $\%$ \\
\hline Low $(0-20)$ & 33 & 20.50 & 11 & 64.71 & 44 & 24.72 \\
\hline Moderate $(21-40)$ & 96 & 59.63 & 6 & 35.29 & 102 & 57.30 \\
\hline Moderate to Severe + Severe $(41-88)$ & 32 & 19.88 & 0 & 0 & 32 & 17.98 \\
\hline Total & 161 & 100.0 & 17 & 100.0 & 178 & 100.0 \\
\hline
\end{tabular}

Fisher's exact: 0.000

In accordance with the older adult's dependence as classified by the FIM, Table 3 shows that caregivers who are helping older adults classified as independent have higher chances of lower burden $(O R=16.76)$ when compared to caregivers who care for older adults with complete dependence and modified dependence 1 . In the same way, caregivers who care for older adults with functional independence have higher chances of lower burden $(O R=5.50)$ when compared with caregivers who care for older adults with modified dependence 2 .

Table 3 - Multiple logistic regression analysis for the factors associated with lower burden of the family caregiver for older adults with functional incapacity, Arapongas, PR, Brazil, 2011

\begin{tabular}{|c|c|c|c|c|c|}
\hline \multirow{2}{*}{$\begin{array}{l}\text { Variables } \\
\text { Sex of caregiver }\end{array}$} & \multirow[t]{2}{*}{ Categories } & \multirow{2}{*}{$\begin{array}{c}\text { OR adjusted } \\
1.00\end{array}$} & \multirow{2}{*}{$\begin{array}{c}\mathbf{p} \\
0.001\end{array}$} & \multicolumn{2}{|c|}{$\begin{array}{c}\text { Confidence } \\
\text { intervals } 95 \%\end{array}$} \\
\hline & & & & 2.61 & 52 \\
\hline & Male & 11.65 & & & \\
\hline \multirow[t]{2}{*}{ Older adult's dependence acc. to FIM } & Complete and modified 1 & 1.00 & 0.001 & 3.33 & 84.25 \\
\hline & Independence & 16.76 & & & \\
\hline \multirow[t]{2}{*}{ Older adult's dependence acc. to FIM } & Modified 2 & 1.00 & 0.026 & 1.22 & 24.67 \\
\hline & Independence & 5.50 & & & \\
\hline
\end{tabular}

Therefore, being a male family caregiver, and caring for an older adult classified as independent by the FIM, shows association with lower burden, in which the results were statistically significant $(p<0.05)$.

\section{Discussion}

In this study, it was evidenced that elderly women with functional incapacity predominate, data which corroborates studies in the literature(16-18). The greater proportion of elderly women in the populational group over 60 years old creates gender inequality in life expectancy, as women live, on average, seven years longer than men. However, the fact that women live longer exposes them to, and makes them susceptible to, functional dependence ${ }^{(19)}$.

Among the conditions related to the principal reason for functional dependence in the older adult, the data is similar to that found in the relevant literature, in which Cerebrovascular Accidents (CVA) and external causes, principally falls, predominate ${ }^{(17)}$.

CVAs are highly prevalent in Brazil, and are associated with elevated rates of morbidity, mortality and also incapacity, being an important public health problem because, in addition to creating costs for the older adult and their family, they also encumber the health system due to the high financial costs of hospitalization and rehabilitation. The risk of CVA begins to rise after 60 years of age and doubles with each decade of life, with arterial hypertension being the main modifiable risk factor ${ }^{(20)}$.

The data indicated in this study in relation to falls reflects a concern with the health of the older adult, as this event is an indicator for the beginning of functional decline, or even as a symptom of a new illness ${ }^{(18)}$. It is extremely important to highlight that falls can lead to a reduction in functional capacity and that, besides psychological and social harm, can lead to economic consequences for the older adult, the family and the 
health systems, increasing the costs related to health care and also lead to the need for care.

The classification of the older adults in this study, according to their degree of dependence, using the FIM, demonstrated that the population studied was concentrated in the classification modified dependence 1 , needing assistance in up to $50 \%$ of the tasks, corroborating studies in the literature ${ }^{(17,21)}$.

It can be considered that functional capacity is a new paradigm for health care for the elderly population and is a great challenge for health professionals seeking to promote healthy ageing, in which the FIM is presented as one of the tools for elucidating the need for care required, to relate the quality of life when this is determined based on activities of daily living and, also, for the recovery of functionality when used at different times in the same individuals(22).

Regarding family caregivers, women, who were married and who were daughters, predominated. The data is in line with that found in the literature ${ }^{(7,8,17)}$. Even given the greater integration of women into the job market, the data reinforces that the role of principal caregiver continues to be assigned to women. Therefore, women take on the care for a dependent being - a role determined, historically, by social and cultural norms(23). However, the situation found in this study is concerning, as the caregiver may be being made responsible for other activities, apart from those dedicated to the dependent older adult as, culturally, women also take on care related to the family ambit, in addition to being integrated in the job market.

When the caregiver age was analyzed, it was ascertained that many of them were aged 60 or over. However, a statistically-significant association was ascertained with caregiver age in relation to the age of the older adult, revealing that older caregivers care in a greater proportion for more elderly older adults, that is, older adults caring for dependent older adults. This situation reveals a concern regarding the quality of the care provided by the caregiver for the older adult with functional incapacity, when one considers the caregivers' health - as many of them take on tasks for which they are not prepared, in addition to neglecting care for themselves, leading them to present physical and emotional conditions which impact negatively on the care provided $(9)$.

The socio-economic level of the older adults' caregivers was analyzed according to the ABEP(15) instrument, with five different categories, and it was found that the present study's data is similar to that of a study with people caring for octogenarians in a municipality in the central region of the state of São Paulo, whose authors identified that $36 \%$ of the caregivers were in Class $\mathrm{C}^{(24)}$.

It stands out that dependence creates greater costs in the care process, and that the purchasing power of the caregivers in this study is relatively low, which may influence the dynamics and in the family and economic aspects and, in many cases, compromises the care given to the older adult.

In this matter, it is emphasized that being prepared to care goes beyond simple availability for the task. It follows that the challenge presented to the health professionals - especially to the nurse - is to provide adequate professional support so as to instrumentalize the caregiver to carry out the care, as well as identifying support networks for the caregiver.

In the evaluation of the family caregiver's burden, the data indicates that the majority of the caregivers had moderate burden, which was also reported in studies in the literature ${ }^{(17,21)}$. In the present research, a statisticallysignificant relationship was identified between the burden in relation to the sex of the caregiver and the degree of the older adult's dependence as evaluated by the FIM. The data found reinforces the relationship of dependence to the caregiver burden, demonstrating that the greater the older adult's dependence, the greater the chances of burden in the caregiver ${ }^{(8)}$.

In relation to sex, it is perceived that this is directly related to the burden, that is, as the burden reported increases, the participation of women in the care increases too; in addition to this, the data shows that the women feel more burdened than do the men, it being observed that one of the factors which contributes to the increase in care burden is gender identity ${ }^{(25)}$.

It is highlighted that caring for a family member with functional incapacity is a task which requires various attributes in the person doing the caring; however, the burden perceived by the caregivers may not present the same intensity, nevertheless it is a fact that many of them take on tasks for which they are not prepared, in addition to neglecting care for themselves, leading them to present physical and emotional conditions ${ }^{(9)}$.

The physical, emotional and socio-economic burden of the care for a family member is immense, complex, and demands a lot of the person who provides the care - in addition to which, this burden can, in a certain way, contribute to the appearance or worsening of ill health. In this way, the burden created by the care process, as well as being a multidimensional concept, is 
also affected by a variety of influences associated with the older adult and the caregiver herself.

\section{Conclusion}

The functional capacity evaluated through the FIM was shown to be associated with the caregiver burden, with lower burden being associated in caregivers who were responsible for the care for older adults with lower levels of dependence, emphasizing that the older adult's functional incapacity was an important predictor for the burden on the caregiver.

In this context, it is extremely relevant to assess the family caregiver's burden, so as to be able to plan actions, adapt the health services, prepare the health professionals to offer appropriate support to the families and to promote strategies which aim to educate on the issue of the ageing process. Therefore, evaluating the caregiver's health must be part of the actions undertaken by the Family Health teams, with the aim of diagnosing influences and developing interventions which contribute to the improvement of the caregiver's quality of life and which may impact positively on the care provided to the older adult.

In the light of this evidence, it becomes necessary, further, to stimulate discussion so as to think about and reflect on the issue which encompasses active ageing, such that actions may be carried out to encourage the promotion and maintenance of functional capacity and the older adult's autonomy, and that programs may be set up which include the health of the caregiver - thus contributing to preventing burden and improving quality of life, in the older adult and the caregiver alike.

\section{References}

1. Martins JJ, Nascimento ERP, Erdmann AL, Candemil MC, Belaver GM, Mortari G. O cuidado no contexto domiciliar: o discurso de idosos/familiares e profissionais. Rev Enferm UERJ. out/dez 2009;17(4):556-62.

2. Veras R. Envelhecimento populacional contemporâneo: demandas, desafios e inovações. Rev Saude Pública. 2009;43(3):548-54.

3. Ministério do Trabalho e Emprego (BR). Classificação brasileira de ocupações: códigos, títulos e descrições. 3.ed. Brasília (DF): Ministério do Trabalho e Emprego; 2010.

4. Ministério da Saúde (BR). Estatuto do idoso. Brasília (DF): Ministério da Saúde; 2003. (Serie E).

5. Bicalho CS, Lacerda MR, Catafesta F. Refletindo sobre quem é o cuidador familiar. Cogitare Enferm. 2008;13(1):118-23.
6. Mayor MS, Ribeiro O, Paúl C. Satisfaction in dementia and stroke caregivers: a comparative study. Rev. LatinoAm. Enfermagem. 2009;17(5):620-4.

7. Domínguez Guedea MT, Damacena FA, Montiel Carbajal MM, Marcobich PO, Álvarez Hernández G, Valdéz Lizárraga $L$, et al. Necessidades de apoio social em cuidadores de familiares idosos mexicanos. Psicol Soc. 2009;21(2):242-9.

8. Gratão ACM, Vale FAC, Roriz-Cruz M, Haas VJ, Lange C, Talmelli LFS, et al. The demands of family caregivers of elderly individuals with dementia. Rev Esc Enferm USP. 2010;44(4):873-80.

9. Blum K, Sherman DW. Understanding the experience of caregivers: a focus on transitions. Semin Oncol Nurs. 2010 Nov;26(4):243-58.

10. Carretero S, Garcés J, Ródenas F, Sanjosé V. The informal caregiver's burden of dependent people: theory and empirical review. Arch Gerontol Geriatr. 2009;49(1):74-9.

11. Nardi EFR, Oliveira MLF. Conhecendo o apoio social ao cuidador familiar do idoso dependente. Rev Gaúcha Enferm. mar 2008;29(1):47-53.

12. Riberto M, Miyazaki MH, Jucá SSH, Sakamoto $H$, Pinto PPN, Battistella LR. Validação da versão brasileira da medida de independência funcional. Acta Fisiátrica. 2004;11(2):72-6.

13. Zarit SH, Zarit JM. The memory and behavior problems checklist: $1987 \mathrm{R}$ and the burden interview (technical report). University Park (PA): Pennsylvania State University; 1987.

14. Scazufca M. Brazilian version of the Burden Interview scale for the assessment of burden of care in careers of people with mental illnesses. Rev Bras Psiquiatr. 2002;24(1):12-7.

15. Associação Brasileira de Empresas de Pesquisa (ABEP) Critério de classificação econômica Brasil. [Internet]. 2008. [acesso 12 maio 2011]. São Paulo; Disponível em: http://www.abep.org.

16. Gonçalves LHT, Costa MAM, Martins MM, Nassar SM, Zunino R. The family dynamics of elder elderly in the context of Porto, Portugal. Rev. Latino-Am. Enfermagem. $2011 ; 19(3): 458-66$.

17. Moreira PHB, Mafra SCT, Pereira ET, Silva VE. Qualidade de vida de cuidadores de idosos vinculados ao Programa Saúde da Família - Teixeiras, MG. Rev Bras Geriatr Gerontol. 2011;14(3):433-40.

18. Fhon JRS, Fabrício-Wehbe SCC, Vendruscolo TRP, Stackfleth R, Marques S, Rodrigues RAP. Accidental falls in the elderly and their relation with functional capacity. Rev. Latino-Am. Enfermagem. 2012;20(5):927-34. 
19. Oliveira-Campos M, Cerqueira MBR; Rodrigues JF Neto. Dinâmica populacional e o perfil de mortalidade no município de Montes Claros (MG). Ciênc Saúde Coletiva. 2011;16(supl):1303-10.

20. Castro JAB, Epstein MG, Sabino GB, Nogueira GLA, Blankenburg $C$, Staszko KF, et al. Estudo dos principais fatores de risco para acidente vascular encefálico. Rev Bras Clin Med. 2009;7(3):171-3.

21. Amendola F, Oliveira MAC, Alvarenga MRM. Qualidade de vida dos cuidadores de pacientes dependentes no Programa Saúde da Família. Texto Contexto Enferm. abr-jun 2008;17(2):266-72.

22. Silveira L, Macagnan JBA, Fuck JAB, Lagana MTC. Medida de independência funcional: um desafio para a enfermagem. Rev Saúde Pública. 2011;4(1):70-83.

23. Karsch UM. Idosos dependentes: famílias e cuidadores. Cad Saúde Pública. maio-jun2003;19(3):861-6.

24. Inouye K, Pedrazzani ES, Pavarini SCI. Octogenários e cuidadores: perfil sócio-demografico e correlação da variável qualidade de vida. Texto Contexto Enferm. 2008;17(2):350-7.

25. Pinto MF, Barbosa DA, Ferreti CEL, Souza LF, Fram DS. Qualidade de vida e sobrecarga de cuidadores de idosos com doença de Alzheimer. Acta Paul Enferm. $2009 ; 22(5): 652-7$. 